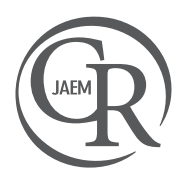

\section{Atrial Fibrillation Due to Electric Shock}

\author{
Elektrik Çarpmasına Bağlı Gelişen Atrial Fibrilasyon
}

\author{
Mustafa İçer ${ }^{1}$, Umut Gülaçtı², Recep Dursun ${ }^{3}$ \\ 'Malatya Devlet Hastanesi Acil Servisi, Malatya, Türkiye \\ ¿Elazığ Devlet Hastanesi Acil Servisi, Elazığ, Türkiye \\ ${ }^{3}$ Van Devlet Hastanesi Acil Servisi, Van, Türkiye
}

\section{ABSTRACT}

Rhythm disorders (transmission problems, tachycardia and arrhythmia) related to electric shock are frequently seen. One of these arrhythmias is atrial fibrillation (AF). A case of atrial fibrillation that occurred due to electric shock and returned to normal sinus rhythm following medical cardiovascular intervention is presented in this paper.

Keywords: Electric shock, atrial fibrillation, amiodarone, electrocardiograph

Received: 08.07.2011 Accepted: 10.07.2011

\section{ÖZET}

Elektrik çarpmasına bağlı ritim bozuklukları ile (iletim sorunları, taşikardi, aritmi) sık karşılaşılır. Bu ritim bozukluklarından birisi de atriyal fibrilasyondur (AF). Bu yazıda elektrik çarpması sonrası oluşan ve medikal kardiyoversiyon sonrası normal sinüs ritmine dönen bir atriyal fibrilasyon olgusu sunulmuştur.

Anahtar Kelimeler: Elektrik çarpması, atrial fibrilasyon, amiodaron, elektrokardiyografi

Geliş Tarihi: 08.07.2011 Kabul Tarihi: 10.07.2011

\section{Giriş}

Gelişen teknolojiye bağlı günümüzde elektrik çarpması olgularına daha sık rastlanmaktadır. Hafif elektrik çarpmalarının sayısı bilinmemekle beraber, Amerika'da yılda 17.000 olgu elektrik çarpmasına bağlı acil servislere başvurmaktadır. Erken dönemde ölümler genellikle ventriküler fibrilasyona bağlıdır (1). Elektrik çarpması sonrası Elektrokardiyografide (EKG) ani başlangıçlı belirgin ST segment yükselmesi ve ritim düzensizlikleri, ekokardiyografide sol ventrikül duvar hareket bozuklukları (hipokinezi, akinezi) ile kardiyak enzim yükseklikleri miyokardiyal tutulumun işaretleridir. Morbidite ve mortalite genellikle farklı elektriksel akım türlerine ve temas yerlerine göre etkilenmektedir. Elektrik çarpmalarında kardiyak etkiler yanında en ciddi yaralanmalar deri ve yüksekten düşmeye bağlı multiorgan yaralanmalarıdır $(2,3)$. Bu vakayı sunmamızın amacı, elektrik çarpmalarına bağlı gelişebilecek ritim bozukluklarını ve lietratür bilgilerini gözden geçirmektir.

\section{Olgu Sunumu}

Daha önce herhangi bir kardiyak rahatsızığı olmayan 36 yaşında erkek hasta, iş yerinde yüksek akım elektrik çarpmasından hemen sonra başlayan çarpıntı ve hafif göğüs ağrısı nedeni ile acil servise getirildi. Başvuru sırasında hastanın şuuru açık, oryante, koopere olup ve Glasgow Koma Skalası 15 olarak değerlendirildi. Özgeçmişinde bir hastalık öyküsü yoktu. Kan basıncı, nabız, solunum sayısı ve pulse oksimetre ile ölçülen oksijen saturasyonu sıra 130/85 mmHg, 114 atım/dk, 18/dk ve \%97 idi. Sağ el parmaklarında tırnak altında hematom ve parmak pulpasında elektrik giriş yanığı mevcuttu; ancak elektrik çıkış yerine rastlanmadı. Diğer sistem muayeneler ve posterior-anterior akciğer grafisi normal idi. İlk çekilen EKG'sinde atrial fibrilasyon (114/dk) vardı (Şekil 1). Laboratuar tetkiklerinde AST: 56 (5-34 U/L), LDH 836 (125-243 U/L), CK:327 (29-168 U/L), CKMB 116 ng/mL, miyoglobin 659 ng/ml olarak ölçüldü ve idrarda eritrosit 300/mL idi. Troponin ve diğer parametreler normal idi. Ekokardiyografisi normal olarak değerlendirildi. Atrial fibrilasyonu için Amiodaron ile medikal kardiyoversiyon tedavisine başlandı (5-7 mg/kg 60 dakikada, sonrasında $1.4 \mathrm{~g} / \mathrm{gün}$ IV infüzyon). Amiodaron tedavisinin dördüncü saatinde EKG normal sinüs ritmine döndü (Şekil 2). Hasta acilde yatışının 3. günü Amiodaron ve Asetil Salisilik Asit önerilerek tabucu edildi. On gün sonra çekilen kontrol EKG'sinde patoloji saptanmadı. 


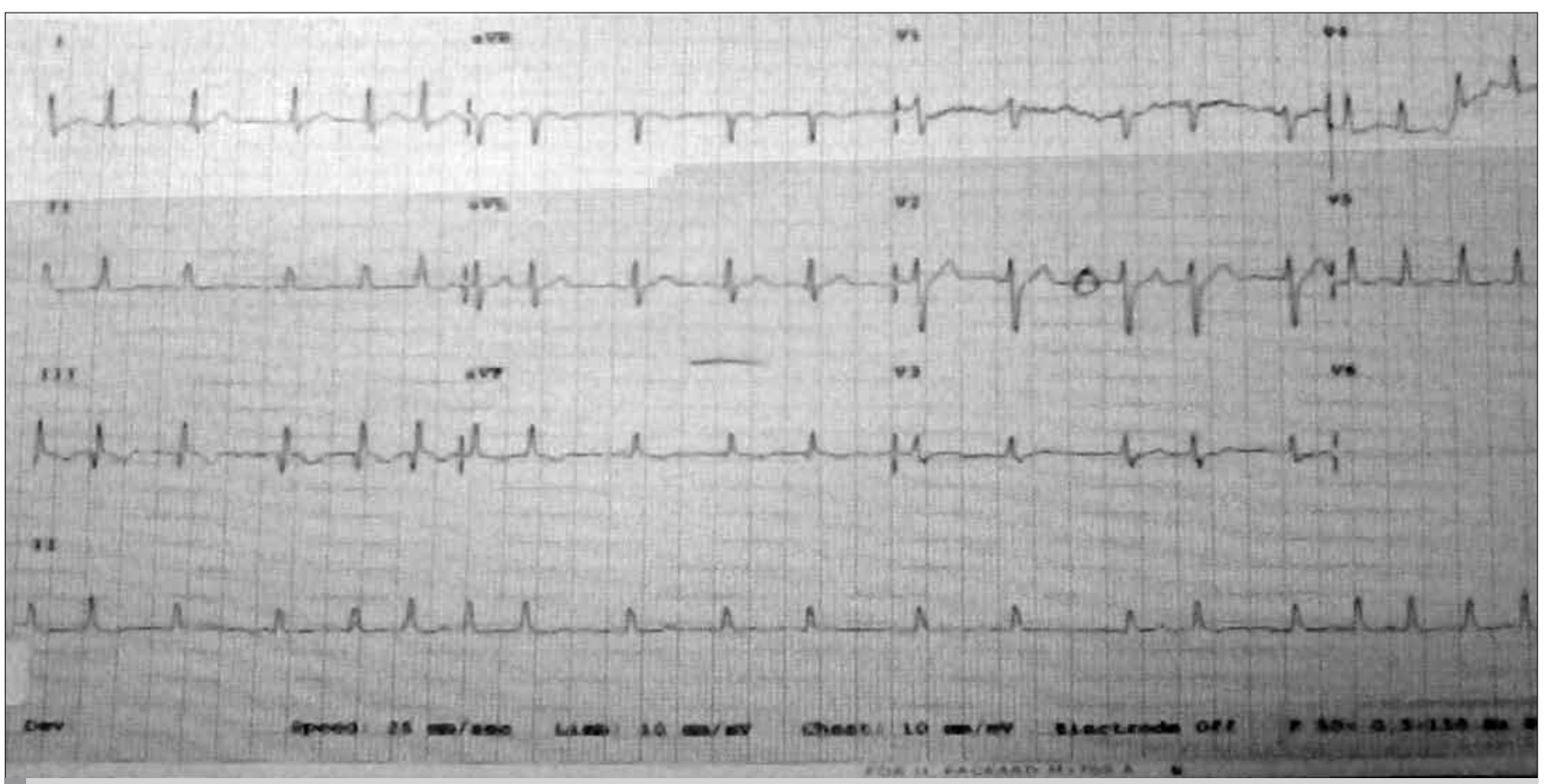

Şekil 1. Elektrik çarpmasından bir saat sonra çekilen EKG

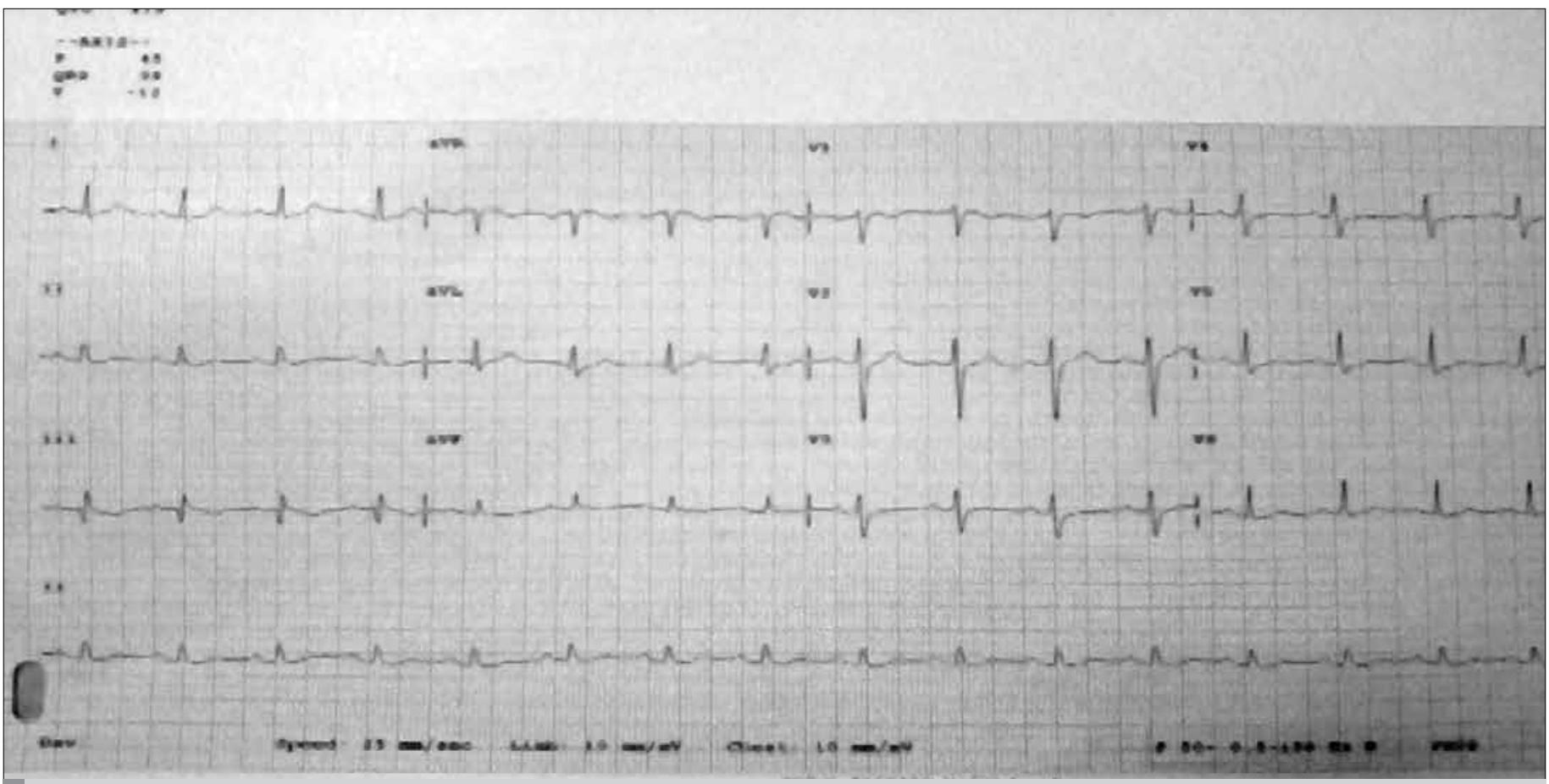

Şekil 2. Tedavinin dördüncü saatinde çekilen EKG

\section{Tartışma}

Elektrik çarpmasına bağlı EKG değişikliklerinden nonspesifik ST segment değişiklikleri ve sinüs taşikardisi en sık görülenleridir. Daha nadir olarak ta QT intervalinin uzaması, dal blokları, atriyal ve ventriküler fibrilasyon, atriyal ve ventriküler prematüre kontraksiyonlar görülür $(4,5)$. Bunun yanında miyokardiyal infarkt, geçici hipertansiyon, sol ventrikül disfonksiyonu, kardiyak rüptür ve aritmi gibi kardiyak etkiler de görülebilmektedir (3). Uzamış QT intervali ventriküler fibrilasyona bağlı ani ölümler için bir risk faktörüdür ve mortaliteyi sekiz kat arttırmaktadır $(6,7)$. Arrowsmith ve Al ve arkadaşlarının (5) çalışmalarında anormal EKG bulguları sırası ile \%3 ve \%67.9 arasında değiştiği bildirilmiştir. Başka değişik çalışmalarda bu oranlar \%14 ile \%54 arasın- 
da olduğu vurgulanmıştır (8, 9). Elektrik çarpmasına bağlı cilt yanığı, düşme gibi travmalar ile birlikte çarpan elektriğin voltaj şiddeti ve akımın vücuttan geçiş yönüne göre kardiyak etkilenimler olabilmektedir (10).

Literatürde elektrik çarpması sonrası gelişen atriyal fibrilasyon olguları nadirdir (11-13). Uzkeser ve ark. (12) elektrik çarpması sonucu AF gelişen medikal tedavinin ikinci gününde normal sinüs ritmine dönen bir olgu bildirmişlerdir. Gözlükaya ve ark. (13) elektrik çarpması sonucu AF gelişen ve IV diltiazem verildikten 20 dakika sonra normal sinüs ritmine dönen bir olgu bildirmişlerdir. Olgumuzda geliş anından itibaren atriyal fibrilasyon vardı. Medikal tedavinin (IV Amiodaron) dördüncü saatinde normal sinüs ritmine döndü. Elektrik çarpmasına bağlı AF tedavisinde hemodinamik bozukluk yoksa beta blokerler, kalsiyum kanal blokerleri ve digital kullanılabilir. Başlangıçta intravenöz formları ile hız kontrolü sağlandıktan sonra oral formları ile idame tedaviye geçilebilir. Ayrıca trombosit agregasyonunu önlemek için heparin ve koroner spazmı çözmek için kalsiyum kanal blokerleri ve nitratlar kullanılabilir. Ancak hemodinamik bozukluk olan hastalarda ise kardiyoversiyon ilk tercih olmalıdır (12). Bununla beraber elektrik çarpmaları multipl bir travmadır ve multidisipliner bir yaklaşım gerektirmektedir (5).

\section{Sonuç}

Elektrik çarpmasına maruz kalan hastalarda her türlü aritmi oluşabilir. Nadirde olsa supravetriküler aritmilerde görülebilir. Şuur kaybı olan, sahada dokümante edilmiş aritmisi olan ve başvuru anında anormal EKG bulguları olan hastalar hem hastanede hem de taburcu edildikten sonra yakın takibe alınmalıdırlar.

\section{Çıkar çatışması}

Yazarlar herhangi bir çıkar çatışması bildirmemişlerdir.

\section{Kaynaklar}

1. Jensen PJ, Thomsen PE, Bagger JP, Norgaard A, Baandrup U. Electrical injury causing ventricular arrhythmias. Br Heart J 1987; 57: 279-83. [CrossRef]

2. Fish RM. Electric injury, part I: treatment priorities, subtle diagnostic factors, and burns. J Emerg Med 1999; 17: 977-83. [CrossRef]

3. Fish RM. Electric injury, Part II: Specific injuries. J Emerg Med 2000; 18: 27-34. [CrossRef]

4. Celebi A, Gulel O, Cicekcioglu H, Gokaslan S, Kututcularoglu G, Ulusoy V. Myocardial infarction after an electric shock: a rare complication. Cardiol J 2009; 16: 362-4.

5. Al B, Aldemir M, Güloğlu C, Kara IH, Girgin S. Epidemiological characteristics of electrical injuries of patients applied to the emergency department. Ulus Travma Acil Cerrahi Derg 2006; 12: 135-42.

6. Sra J, Dhala A, Balanck Z, Deshpande S, Cooley R, Akhtar M. Sudden cardiac death. Curr Probl Cardiol 1999; 24: 461-538. [CrossRef]

7. Lambardi F. The QT interval and QT dispersion: 'the smaller, the better'! Eur Heart J 1998; 19: 1279-81.

8. Arrowsmith J, Usgaocar RP, Dickson WA. Electrical injury and the frequency of cardiac complications. Burns 1997; 23: 576-8. [CrossRef]

9. Butler ED, Gant TD. Electrical injuries, with special reference to the upper extremities. Am J Surg 1977; 134: 95-9. [CrossRef]

10. Uzkeser M, Aksakal E, Emet M, Çakır Z, Aslan S. Elektrik Çarpmasına Bağlı Gelişen Akut Miyokart Enfarktüsü. Konuralp Tıp Dergisi 2011; 3: 23-5.

11. Akdemir R, Gunduz H, Erbilen E, Ozer I, Albayrak S, Unlu H, et al. Atrial fibrillation after electrical shock: a case report and review. Emerg Med J 2004; 21: 744-6. [CrossRef]

12. Uzkeser M, Aksakal E, Aköz A, Aslan Ş, Emet M, Çakır Z. Elektrik Çarpmasına Bağlı Atriyal Fibrilasyon. JAEM 2009; 8: 38-40.

13. Gözlükaya A, Serinken M. Elektrik Çarpmasına Bağıı Gelişen Atriyal Fibrilasyon. JAEM 2010;1:27-29. 